\title{
Quality of Life and Stress among Obsessive Compulsive Disorder Caregivers and General Population
}

\author{
Akshara Goel $^{1 *}$, Dr. Roopali Sharma ${ }^{2}$
}

\section{ABSTRACT}

The current study aimed at comparing the Quality of Life and Stress among Obsessive Compulsive Disorder caregivers and General population. It was hypothesised that the Quality of Life will be poor in Obsessive Compulsive Disorder caregivers and their level of Stress will be high in comparison with General population. There would be a significant relationship in the Quality of Life and Stress in Obsessive Compulsive Disorder caregivers. The study proves that the Quality of Life is superior in General population than Obsessive Compulsive Disorder caregivers, whereas the level of Stress is higher in Obsessive Compulsive Disorder caregivers. There is also a significant relationship between Quality of Life and Stress in Obsessive Compulsive Disorder caregivers.

Keywords: Quality of Life, Stress, Obsessive Compulsive Disorder, Caregivers, General, Population

Obsessive-compulsive disorder (OCD) is classified as an anxiety disorder marked by Obsessions accompanied by repeated attempts to suppress these thoughts through compulsions.

- Obsessions are involuntary, seemingly uncontrollable thoughts, images, or impulses that occur repeatedly in your mind. They are often disturbing and distracting.

- Compulsions are behaviours or rituals that you feel driven to act out repeatedly. Usually, these compulsions are performed in an attempt to make obsessions go away.

- Most people with obsessive-compulsive disorder (OCD) fall into one of the following categories:

- Washers are afraid of contamination. They usually have cleaning or hand-washing compulsions.

- Checkers repeatedly check things (oven turned off, door locked, etc.) that they associate with harm or danger.

\footnotetext{
${ }^{1}$ Amity Institute of Psychology and Allied Sciences, Amity University, Noida, India

${ }^{2}$ Associate Professor, Amity Institute of Psychology and Allied Sciences, Amity University, Noida, India *Responding Author

(C) 2016 I A Goel, R Sharma; licensee IJIP. This is an Open Access Research distributed under the terms of the Creative Commons Attribution License (http://creativecommons.org/licenses/by/2.0), which permits unrestricted use, distribution, and reproduction in any Medium, provided the original work is properly cited.
} 
- Doubters and sinners are afraid that if everything isn't perfect or done just right something terrible will happen or they will be punished.

- Counters and arrangers are obsessed with order and symmetry. They may have superstitions about certain numbers, colours, or arrangements.

- Hoarders fear that something bad will happen if they throw anything away. They compulsively hoard things that they don't need or use.

Signs and Symptoms of Obsessive Compulsive Disorder in Adults :

- Common Obsessive Thoughts

- Fear of being contaminated by germs or dirt or contaminating others.

- Fear of causing harm to yourself or others.

- Intrusive sexually explicit or violent thoughts and images.

- Fear of losing or not having things you might need.

-Order and symmetry: the idea that everything must line up "just right”.

- Superstitions; excessive attention to something considered lucky or unlucky.

- Excessive focus on religious and moral ideas.

- Common Compulsive Behaviour include :

- Excessive double-checking of things, such as locks, appliances, and switches.

- Repeatedly checking in on loved ones to make sure they're safe.

- Counting, tapping, repeating certain words, or doing other senseless things to reduce anxiety.

- Spending a lot of time washing or cleaning.

- Ordering or arranging things "just so".

- Praying excessively or engaging in rituals triggered by religious fear.

- Accumulating "junk" such as old newspapers or empty food containers.

\section{Caregivers of Obsessive Compulsive Disorder patients :}

In India, more than $90 \%$ of patients live with their families. The family caregiver plays multiple roles including taking day-to-day care, supervising medications, taking the patient to the hospital and looking after the financial needs. Carers of people with Obsessive Compulsive Disorder have to deal with many emotions that arise as a consequence of living with and caring for a sufferer. The family caregiver also has to bear with the behavioural disturbances in the patient. . Thus, the family caregiver experiences considerable stress and burden and needs help in coping with it. These difficult feelings arise from the impact of the Obsessive Compulsive Disorder on your relationship and environment and because it is so hard to see someone close to you either battling or in despair over thoughts and behaviours.

\section{STRESS}

Stress is defined as a mental or emotional strain or tension resulting from adverse or demanding circumstances.

- It affects both body and mind 
- People under large amount of stress can become tired, sick and unable to concentrate or think clearly.

- Caregivers stress can be particularly damaging, as its chronic, long term challenge. People may face years or even decades of caregiving responsibilities. When the caregivers stress puts their health at risk, it affects their ability to provide care.

\section{NEED FOR THE STUDY}

- There is lack of research on this topic especially in the field of Quality of life of Obsessive Compulsive Disorder Caregivers.

- The family caregiver experiences considerable stress in caring for the patient and has remained a neglected lot.

- The level of Stress they face has not being measured so far.

- The busy and hectic lifestyle of the general population has taken a toll on their quality of life and causes stressful factors like blood pressure, heart problems, etc.

\section{LITERATURE REVIEW}

Rodrigues Torres, Travenisk Hoff, Roberto Padovani , Ramos-Cerqueira , 2012, found factors such as perception of patient's dependence, interference in caregiver's personal life, feeling of irritation or intolerance, insecurity, guilt and embarrassment were found to be greatly associated with OCD severity and quality of life of caregivers. with increase in the level of severity of OCD, they found that there has been an increase in the poorer quality of life of caregivers of OCD as well. Female caregivers were found to be severely affected than male caretakers

Grover and Dutta, 2011, found that there existed higher objective burden in case of OCD caregivers. Factors such as age of the patient, duration of illness, duration of treatment, financial burden and perception of poorer mental health affected both physical health domain and psychological quality of life. it was observed that disruption of family leisure and interruption caused due to OCD patients lead to poorer quality of life in care givers. Hence it was recommended that quality of life of both caregivers as well as OCD patients should be taken care off.

Vikas, Avasthi and Sharan, 2009, found that OCD caregivers experienced burden in several areas and was supposed to accommodate with the patient's behaviour as well. When comparing with depressed patients, OCD had a better quality of life and were less disabled but, their caregivers were more burdened and to accommodate to greater degrees. They have to adjust with various domains in relation to OCD in order to cope with poorer quality of life that results as a part of dealing with OCD patients.

Romos, Torres and Vitorino, 2008, evaluated different socio demographic and clinical factors like psychological morbidity, emotional burden and level of accommodation psychological morbidity, and level of family accommodation in caregivers of OCD patients. They found that caregivers of OCD patients experience high level of burden as well as psychological morbidity. 
And thus the authors suggest that they should be provided with orientation and support in order to minimize their emotional impact

Wenzke and Scroll, 2006, found, that quality of life of relatives of patients of OCD, was comparatively low than those of the general population. There existed an adverse effect on the quality of life of relatives of OCD patient. Both their physical health domains as well as mental health domains are found to suffer. Thus it is suggested that focus should be made on how their lives can be improvised and healthy life style can be introduced to them

\section{AIM AND OBJECTIVES}

The aim of this study is to analyse the quality of life and stress of Obsessive Compulsive Disorder caregivers with the general population.

The Objectives:

- Focus on the adverse effects on the quality of life of caregivers of Obsessive Compulsive Disorder.

- The level of stress they perceive in caring for the patient.

- The quality of life and the stress perceived by the general population.

\section{Hypothesis}

- The quality of life of Obsessive Compulsive Disorder caretakers will be poor in comparison to general population.

- Level of Stress will be high in Obsessive Compulsive Disorder Caretakers in comparison to general population

- There will be significant relationship among Quality of Life and level of Stress in Obsessive Compulsive Disorder Caretakers.

\section{Sample}

\begin{tabular}{c|c|c|}
$\begin{array}{c}\text { Age of Obsessive } \\
\text { Compulsive Disorder } \\
\text { Patients }\end{array}$ & $\begin{array}{c}\text { Obsessive } \\
\text { Compulsive Disorder } \\
\text { Caregivers }\end{array}$ & General Population \\
\hline $20-40$ years & 30 & 30 \\
\hline
\end{tabular}

\section{Research Design}

The research design of the particular study will be ex-post facto design.

Ex-post facto research design is a non-experimental research technique in which pre existing groups are compared on some dependent variable. 


\begin{tabular}{|c|c|c|}
\hline VARIABLES & \multicolumn{3}{|c|}{ SAMPLE } \\
\hline & $\begin{array}{c}\text { Obsessive } \\
\text { Compulsive } \\
\text { Disorder } \\
\text { Caregivers }\end{array}$ & General Population \\
\hline Quality Of Life & 30 & 30 \\
\hline Stress & 30 & 30 \\
\hline
\end{tabular}

Tools

\begin{tabular}{|c|c|c|c|c|}
\hline S.No. & $\begin{array}{c}\text { Name of } \\
\text { Psychological } \\
\text { Tool }\end{array}$ & Developed By & Year & $\begin{array}{l}\text { Number of } \\
\text { Items }\end{array}$ \\
\hline 1. & $\begin{array}{c}\text { WHOQOL- } \\
\text { BREF }\end{array}$ & $\begin{array}{c}\text { The WHOQOL } \\
\text { group }\end{array}$ & 1996 & 26 \\
\hline 2. & $\begin{array}{c}\text { Perceived Stress } \\
\text { Scale }\end{array}$ & Sheldon Cohen & 1994 & 10 \\
\hline 3. & $\begin{array}{c}\text { Personal } \\
\text { Information } \\
\text { Schedule }\end{array}$ & Researcher & 2015 & 8 \\
\hline
\end{tabular}

\section{Statistical Analysis}

After data collection, Statistical Analysis will be done with the help of statistical methods like Mean, Standard Deviation, t score, etc.

\section{RESULTS AND DISCUSSION}

The study shows that Obsessive Compulsive Disorder caregivers have a poor Quality of Life in Comparison to the General population. The level of Stress is high in OCD caregivers and there also exists a significant relationship in the Quality of Life of OCD caregivers. Physical health aspect of QOL is low in OCD caretakers than in comparison to the General population. General population has a higher level of Physical health, psychological health as well as Environmental health aspect of QOL than in comparison to OCD caretakers.

Table: 1- Comparison of QOL between OCD Caretakers and General Population

\begin{tabular}{|l|l|l|l|l|l|}
\hline & N & Mean & SD & t test & P \\
\cline { 1 - 4 } OCD Caregivers & 30 & 201.7 & 72.59649 & 5.65 & Sig** \\
\cline { 1 - 4 } General Population & 30 & 273.4 & 125.38 & & \\
\hline
\end{tabular}

$* * \mathrm{p}<.01$ 


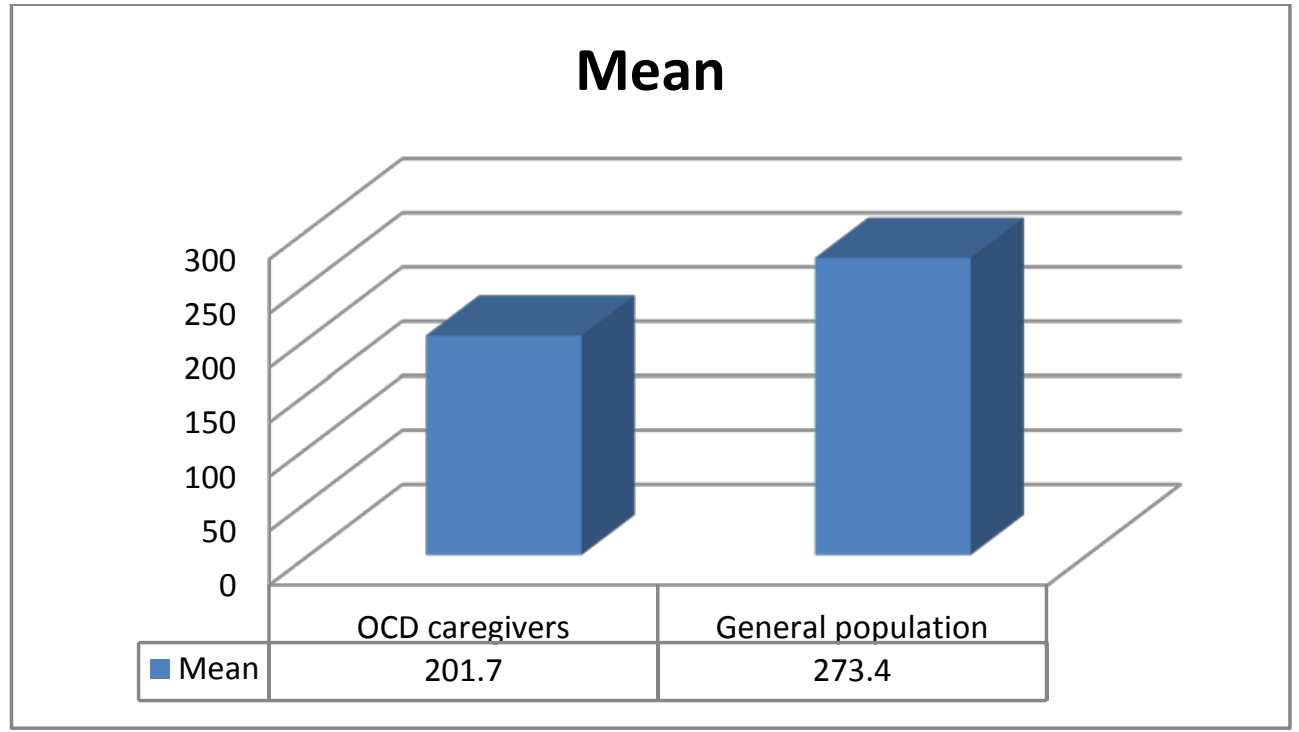

The QOL of OCD caretakers is poor in comparison with General population. The t value (5.65) is significant at .01 level.

Table: 2- Comparison of Stress between OCD caregivers and General Population

\begin{tabular}{|l|l|l|l|l|l|}
\hline & N & Mean & SD & T test & probability \\
\hline OCD Caregivers & 30 & 26.8 & 5.27 & 8.77 & Sig** \\
\cline { 1 - 4 } & & & & & \\
\cline { 1 - 4 } & 30 & 17.7 & 5.22 & & \\
\hline
\end{tabular}

$* * \mathrm{p}<.01$

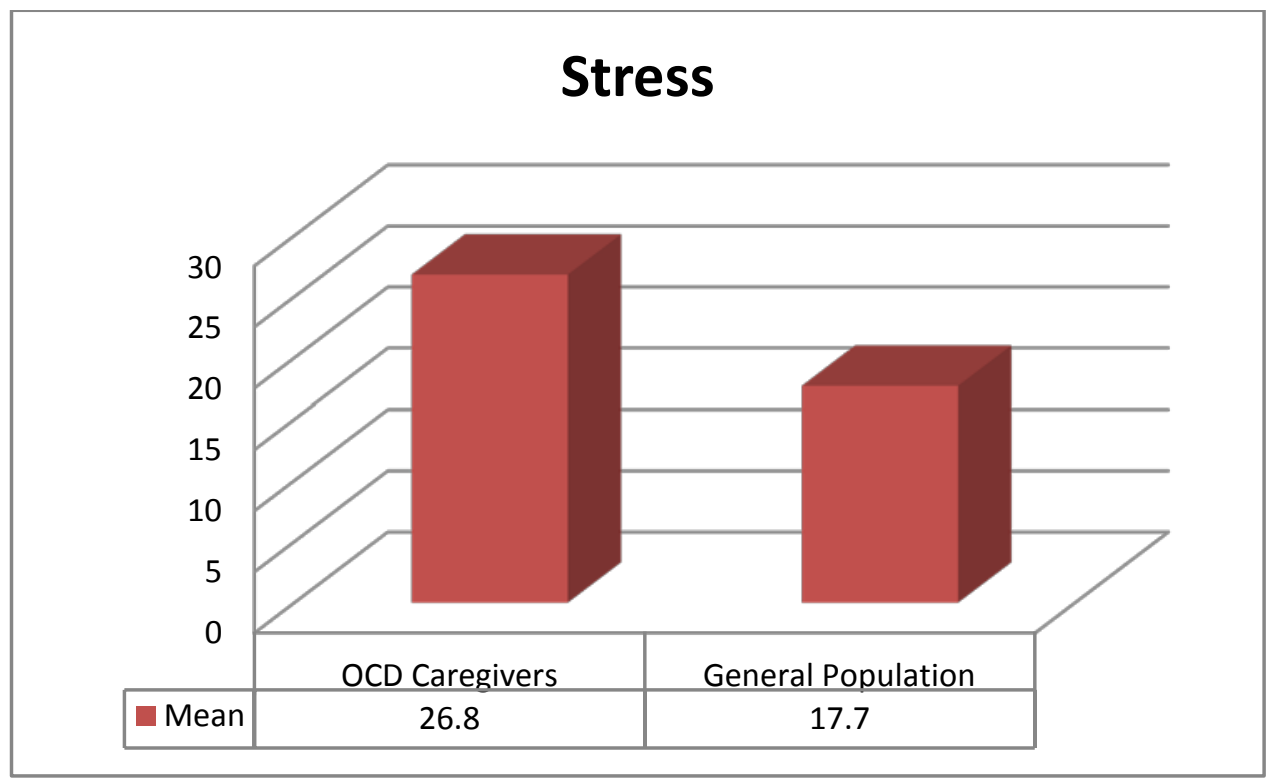

The level of Stress is higher in OCD caregivers than General population. The t value (8.77) of Stress among OCD caregivers and General population is significant at .01 level. 
Quality of Life and Stress among Obsessive Compulsive Disorder Caregivers and General Population

Table: 3- Comparison of physical health as an aspect of QOL between OCD Caretakers and General Population

\begin{tabular}{|l|l|l|l|l|l|}
\hline & N & Mean & SD & T test & probability \\
\cline { 1 - 4 } OCD Caretakers & 30 & 49.8 & 14.05 & 4.57 & \multirow{2}{*}{ Sig** } \\
\cline { 1 - 3 } General Population & 30 & 66.33 & 16.94 & & \\
\hline
\end{tabular}

$* * \mathrm{p}<.01$

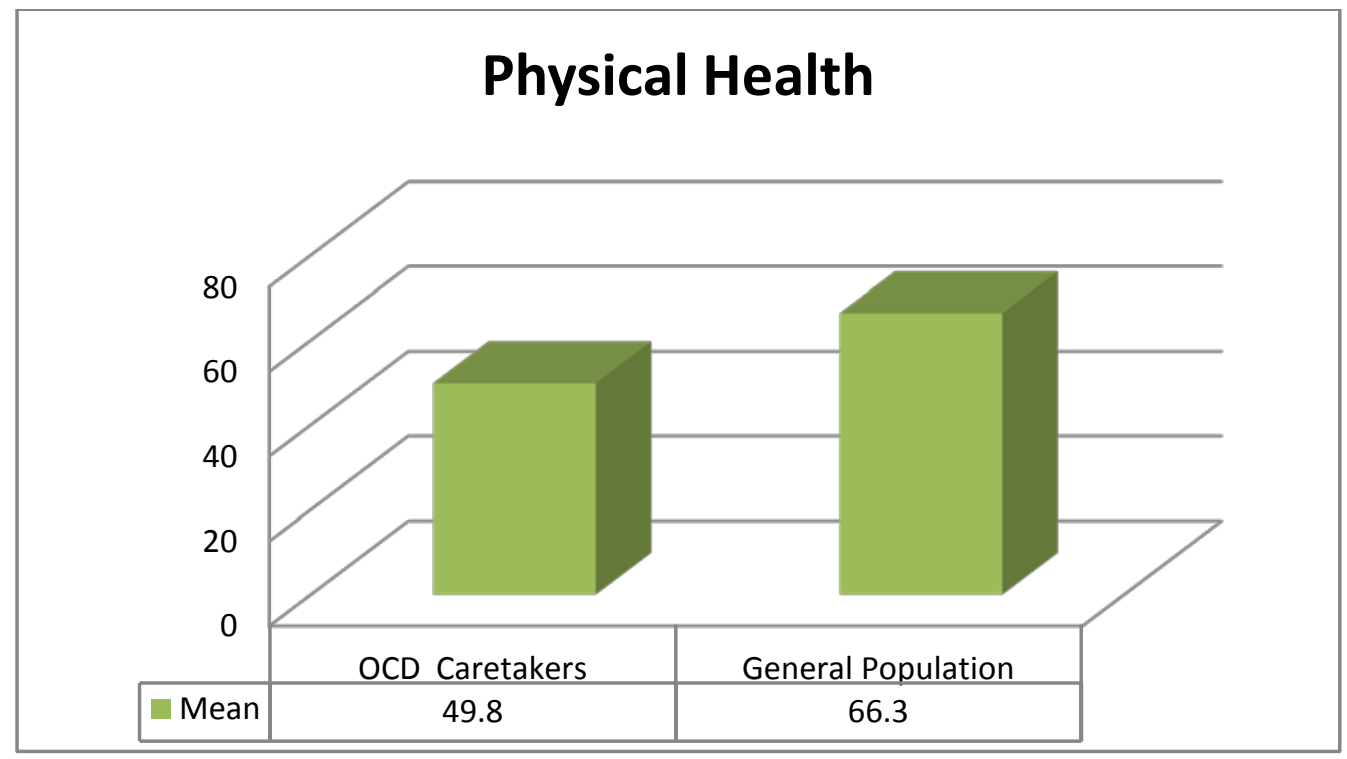

The physical health of General population is better than OCD caregivers. The t value (4.57) of physical health domain between OCD caretakers and general population is significant at .01.

Table: 4- Comparison of psychological domain as an aspect of QOL between OCD Caretakers and General Population

\begin{tabular}{|c|c|c|c|c|c|}
\hline & $\mathbf{N}$ & Mean & SD & T test & probability \\
\hline OCD Caretakers & 30 & 48.8 & 12.85 & \multirow[t]{2}{*}{6.49} & Sig** \\
\hline General Population & 30 & 64.83 & 13.30 & & \\
\hline
\end{tabular}




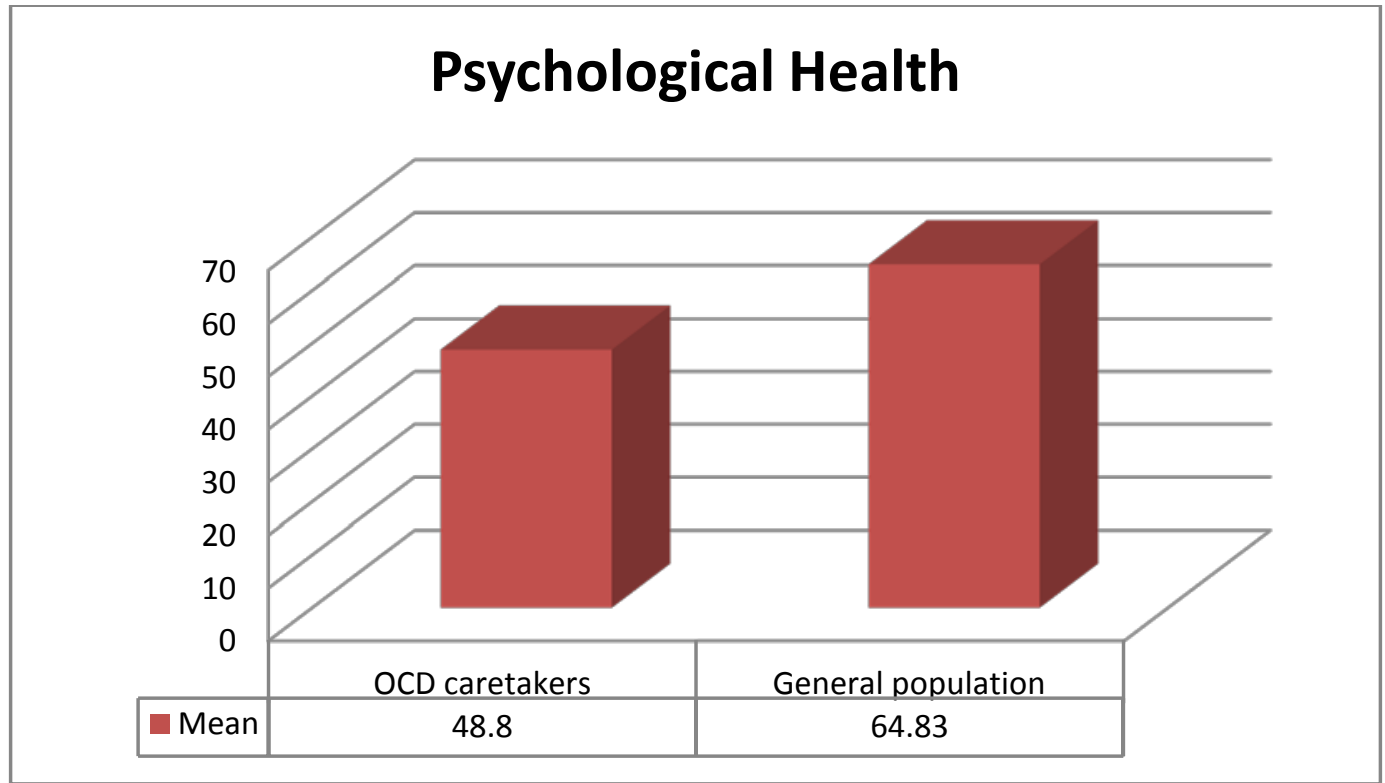

The Psychological QOL is superior in General population than OCD caregivers. The t value (6.49) of psychological domain OCD caretakers and general population is significant at .01.

Table: 5- Comparison of Social Relationships as an aspect of QOL between OCD Caretakers and General Population

\begin{tabular}{|l|l|l|l|l|l|}
\hline & N & Mean & SD & T test & probability \\
\cline { 1 - 4 } OCD Caretakers & 30 & 49.1 & 14.63 & 4.47 & **Sig \\
\cline { 1 - 4 } General Population & 30 & 67.93 & 18.82 & & \\
\cline { 1 - 3 } & & & & & \\
\hline
\end{tabular}

$* * \mathrm{p}<.01$

\section{Social Relationships}

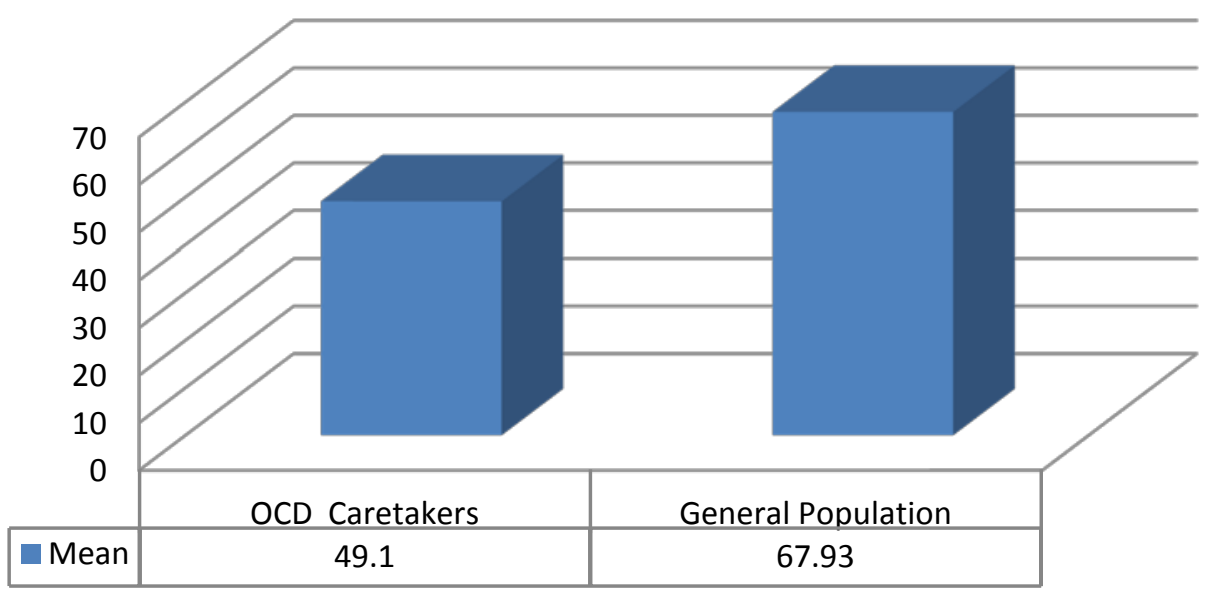


Social Relationships QOL is better in General population than OCD caregiver. The t value (4.47) is significant at .01 level.

Table: 6- Comparison of Environment domain as an aspect of QOL between OCD Caregivers and General Population

\begin{tabular}{|l|l|l|l|l|l|}
\hline & N & Mean & SD & T test & probability \\
\hline OCD Caregivers & 30 & 54 & 12.93 & 6.23 & Sig** \\
\cline { 1 - 4 } & & & 11.76 & & \\
\cline { 1 - 4 } & 30 & 74.33 & & & \\
\hline
\end{tabular}

${ }^{* *} \mathrm{p}<.01$

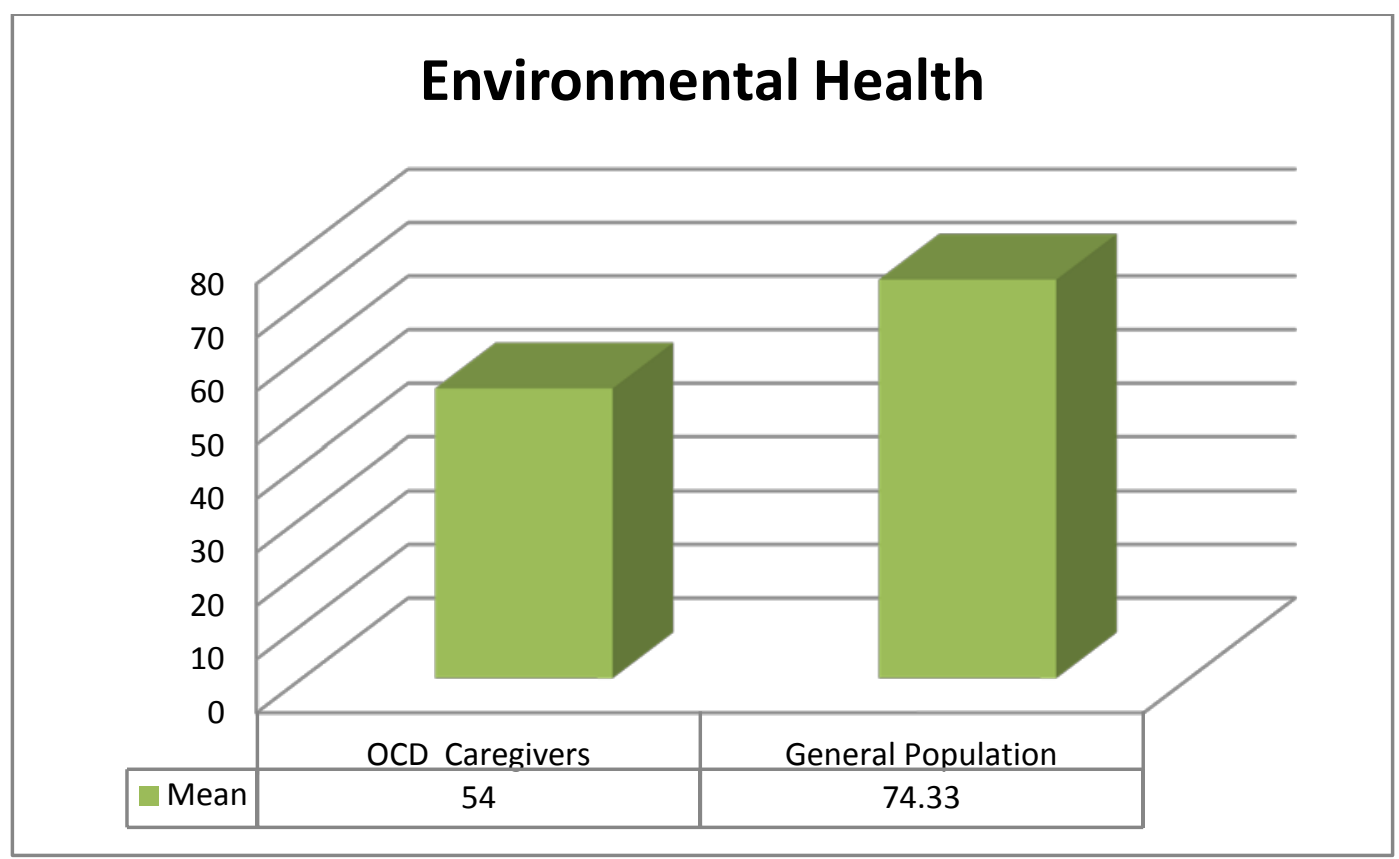

The environmental QOL is superior in General population than OCD caregivers. The t value (6.23) is significant at .01 level.

\section{DISCUSSION}

The present study aimed to study the QOL and Stress among OCD Caregivers and General population. The sample comprised of 60 participants (30 from General population and 30 from OCD caretakers). The test used for QOL is WHOQOL-BREF and for Stress is Perceived Stress Scale. Mean, Standard Deviation and t-test scores were calculated to study the significant relationship.

While compares the mean and t value of the QOL of the caregivers of OCD patients and the General population, it is observed that the t value (5.65) of the QOL among caregivers of OCD and General population is significant. The mean value of OCD caregivers was 201.7 and that of General population was 273.4. Thus resulting that General population has a higher mean value 
than OCD caretakers. Further from the graphical representation we can see that General population has a superior QOL than OCD caregivers. QOL is considered as an overall wellbeing of individuals. According to the authors, Wenzke and Scroll (2006), the QOL of relatives of patients with OCD was comparatively low than the General population.

The comparison of Stress level among OCD caretakers and General population shows the t value (8.77) among both the variables is significant. The mean value of OCD caregivers was 26.8 and that of General population was 17.7, thus signifying that OCD caregiver has a higher mean value than the General population. Further from the graphical representation we can see that the level of Stress is higher in the caregivers of OCD than the General population. Thus Stress is a state of tension or mental or emotional strain resulting from adverse or demanding circumstances by caring for a family member with OCD. Cicek, Kayhan .et.al (2010), found that the level of stress among caregivers of OCD patients is really high. Wenzke and Scroll (2006), the QOL of relatives of patients with OCD was comparatively low than the General population. Both their physical health domains as well as mental health domains are found to suffer.

The comparison of Physical Health as an aspect of QOL among OCD caretakers and General population shows the $t$ value (4.57) among the OCD caretakers and General population is significant. The mean value of the caregivers of OCD was 49.8 and that of General population was 66.3. Thus indicating that General population has a superior level of physical health than OCD caretakers.

While comparing the mean and t value of Psychological aspect of QOL among OCD caregivers and General population, it is observed that the $t$ value (6.49) between both the variables is significant. The mean value of caretakers of OCD was 48.8 and that of General population was 64.83, thus indicating that the mean of General population is higher. Furthermore from the graph we can see that Psychological aspect of QOL is better in General population than OCD caretakers. Rodrigues Torres and Travenisk Hoff (2012) found factors such as interference caregiver's personal life, feeling of irritation or intolerance were found to be greatly associated with QOL of caregivers.

While comparing of mean and t score of Social Relationships as an aspect of QOL among caregivers of OCD and General population, the $t$ score of OCD caregivers and General population was 4.47 , resulting in a significant relationship. The mean value of Obsessive Compulsive Disorder caregivers was 49.1 and that of General population was 67.93, thus indicating that the mean of General population is higher. Furthermore from the graph we can see that the Social Relationships aspect of QOL is better in General population than the OCD caregivers.

The comparison shows the mean and t values of Environmental QOL among OCD caregivers and General population, the t score (6.23) among both the variables is significant. The mean value of Environmental Health of OCD caregivers was 54 and that of General population was 74.33, thus indicating that the mean of General population is higher than that of OCD caregiver. 
Furthermore from the graph we can see that the General population has a superior Environmental Health than the caregivers of OCD patients. Grover and Dutta (2011), observed that disruption in family leisure and interruption caused due to OCD patients leads to poorer QOL among caregivers.

In this study the results shows that the overall Quality including domains physical health, psychological health, social relationships and environmental health is superior in General population. Physical health includes pain and discomfort, work capacity, dependence on medicinal substances and aids, sleep and rest. Psychological health incorporates negative and positive feelings, body image, self-esteem and concentration. Social relationships include personal relationships, social support and sexual activity whereas environmental domain includes financial resources, freedom, home environment, health and social care, physical safety and security and physical environment. All these factors are poor in OCD caregivers than the General population. Stress is higher in the caregivers of OCD.

\section{HYPOTHESES TESTING}

$>$ The QOL of OCD caretakers will be poor in comparison to general population. There is a significant difference between the QOL of OCD caretakers and General population. It is proved.

$>$ Level of Stress will be high in OCD Caretakers in comparison to general population There is a significant difference in the level of Stress among OCD caretakers and General population. It is proved.

$>$ There will be significant relationship among QOL and level of Stress in OCD Caretakers The QOL and Stress in OCD caretakers have a significant relationship. It is proved.

\section{CONCLUSION AND SUMMARY}

The present study aimed to study the QOL and Stress among OCD Caregivers and General population. The sample comprised of 60 participants (30 from General population and 30 from OCD caretakers). The test used for QOL is WHOQOL-BREF and for Stress is Perceived Stress Scale. Mean, Standard Deviation and t-test scores were calculated to study the significant relationship.

\section{FINDINGS}

The study conducted reveals that there is a significant difference in the QOL of OCD caretakers and General population on the domains of physical, psychological, environmental and social relationships aspect of QOL among OCD and General population. It also reveals that there is a significant difference in the level of Stress of caregivers of OCD and General population. 


\section{FURTHER SUGGESTIONS AND LIMITATIONS:}

$>$ It could be done as a Qualitative study (observations and interviews).

$>$ The research can be done by making comparisons between male and female caregivers of OCD and General population.

$>$ Other dimensions can be added and used for understanding.

\section{FUTURE IMPLICATIONS:}

The present study examines the QOL and Stress among OCD caregivers and General population.

It was found that there is a significant difference in the QOL among OCD caregivers and General population. The domains of QOL include physical health, psychological health, emotional health and social relationships. There is also a significant difference in the level of Stress among OCD caregivers and General population.

\section{REFERENCE}

Cerqueira, R., \& Torres, A. (2008). Emotional burden in caregivers of obsessive compulsive disorder. The Official Journal of AADA, 25(12), 1020-1027. Retrieved December 7, 2014.

Cohen, S. (2005). Measuring the self perception of stress. Retrieved August 9, 2014.

Freeman, J., \& Garcia, A. (2008). Early Childhood OCD: Preliminary Findings from a familybased cognitive behavioral approach. Journal of American Academy of Child and Adolescent Psychiatry, 47(5), 593-602. Retrieved December 6, 2014.

Grover, S., \& Dutt, A. (2011). Perceived burden and quality of life of caregivers in obsessivecompulsive disorder. Psychiatry and Clinical Neurosciences, 65(5), 416-422. Retrieved December 26, 2014

Hart, J. (2015). Road map to recovery: Families of adult OCD sufferers living at home. Retrieved August 11, 2014

Laidlaw, T., \& Falloon, I. (n.d.). The stress for caring for people for Obsessive Compulsive Disorder. Community Mental Health Journal, 35(5), 443-450. Retrieved December 6, 2014

Pomfrey, E. (2015, January 1). What is stress. Retrieved February 3, 2015, from http://www.tm.org/resource-pages/222-what-is-stress

Robinson, L., \& Smith, M. (2012). Obsessive Compulsive Disorder. Retrieved August 9, 2014.

Smith, M., \& Segal, R. (n.d.). Stress symptoms, signs and causes. Retrieved December 7, 2014, from http://www.helpguide.org/articles/stress/stress-symptoms-causes-and-effects.htm

Storch, E., \& Pence Jr, S. (2008). Parental Experiences of Having a Child with ObsessiveCompulsive Disorder: Associations with Clinical Characteristics and Caregiver Adjustment. Journal of Child and Family Studies, 18(3), 249-258. Retrieved December 26, 2014 
Storch, E., \& Geffken, G. (2010). Family Accommodation in pediatric obsessive compulsive disorder. Journal of Clinical Child and Adolescent Psychiatry, 36(2), 207-216. Retrieved December 7, 2014.

Strong, K. (2007, February 27). Nine, Ten, Do it again- A book for those with OCD and their families. Retrieved August 7, 2015.

Torres, A., \& Hoff, N. (2012). Dimensional analysis of burden in family caregivers of patients with obsessive-compulsive disorder. Psychiatry and Clinical Neurosciences, 66(5), 432441. Retrieved December 26, 2014

Understanding and managing stress. (2012, January 1). Retrieved December 8, 2014, from http://www.psychology.org.au/assets/files/stresstipsheet.pdf

Vikas, A., \& Avasthi, A. (2009). Psychosocial Impact of Obsessive-Compulsive Disorder on Patients and Their Caregivers: A Comparative Study With Depressive Disorder. International Journal of Social Psychiatry, 57(1), 45-56. Retrieved December 8, 2014.

Waters, T., \& Barette, P. (2000). The Role of the Family in Childhood Obsessive-Compulsive Disorder. Clinical Child and Family Psychology Review, 3(3), 173-184. Retrieved December 6, 2014

Wenzke, K., \& Kroll, M. (2006). Quality of life of relatives of patients with obsessivecompulsive disorder. Comprehensive Psychology, 47(6), 523-527. Retrieved December 26, 2014 